\title{
COMPETENCES OF MANAGEMENT ACCOUNTING SYSTEMS IN MANAGING ENVIRONMENTAL COSTS OF LISTED COMPANIES IN SRI LANKA
}

\author{
Indrani, M. W. ${ }^{1}$, Naidoo, M. $^{2} \&$ Wickremasinghe G. $^{2}$ \\ ${ }^{1}$ Department of Accounting and Finance, University of Ruhuna, Sri Lanka \\ ${ }^{2}$ Victoria University Business School, Victoria University, Australia
}

\begin{abstract}
This study explores the way and the extent to which listed companies in Sri Lanka manage environmental costs through their management accounting (MA) systems.Applying Mixed Method Research approach; data were collected from 42 listed companies representing five industry sectors in Sri Lanka, through a survey followed by discussions with financial executives and environmental officers of companies. Further, it reviewed National Environmental Act of Sri Lanka for legislation enacted for sampled companies. The main tools of analysis were frequency tables for quantitative data, and qualitative data were analyzed linking them with quantitative analysis and, thus providing expressive detailed interpretations for the phenomena under investigations. Findings indicate that even though all companies are bounded by legislation to take environmental management (EM) initiatives to prevent and control pollution, the MA systems of most companies have not been improved accordingly to incorporate environmental costs and related performance measures. All companies used to take EM measures by making adjustments to existing financial accounting/MA systems which were initiated mainly to facilitate regular business activities. These practices thus, demonstrate lower potential for companies in managing EM costs. Competencies of MA techniques considered differ one to another in managing EM costs, showing greater importance for traditional MA techniques like budgeting, products costing than modern MA techniques like kaizen costing, balanced scorecards. Conversely, the Plantation sector shows greater ability in managing environmental costs through their activity based costing systems implemented by all in the sector. It suggests companies to establish appropriate accounting systems and performance measures which are capable of identifying and managing environmental costs precisely. It also suggests improving awareness among all personnel including accounting staff on how to manage environmental costs through such systems ensuring legal compliances, profitability and survival of the business.
\end{abstract}

Keywords: MA systems, MA techniques, environmental costs, listed companies, industry sectors 


\section{Introduction}

Of late, many countries around the world give more attention to environmental concerns together with related costs, revenues and benefits. Environmental costs lead to economic issues and societal issues that are both internal and external to the organization. In this respect, scholars contend that traditional accounting practices do not provide sufficient information in managing environmental costs (International Federation of Accountants-IFCA, 2005). Similarly, Vasile and Man (2012) state that traditional accounting techniques are unable to provide apposite structures that can facilitate to detect all required data because they mostly concern with the costs of resources employed and their aggregation, but no attention to associated activities. Consequently, many potential environment related costs may be misplaced within the indirect costs.

To fill this gap, the emerging field of Environmental Management Accounting (EMA) has been receiving increasing attention. Excessive curiosity on the environmental performance of organizations has shown by internal and external stakeholders predominantly in private sector companies (IFCA, 2005). For an organization to effectively manage the environmental pressure, and costs and benefits, it needs expertise in different areas, such as environmental, technical, accounting and finance, marketing and public relations and general management (IFAC, 2005). Accountants have a special role to play in resolving this issue because of their access to the relevant monetary data and information systems, their ability to improve or verify the
International Journal of Accounting \& Business Finance Vol.6.No.2 December 2020 Issue. pp. 139 - 157

quality of such information and their skills in using that information to help make sound business decisions in areas such as investment appraisal, budgeting and strategic planning (IFAC, 2005).

In this respect, Wilmshurst and Frost (2001) stated that decisions that may have environmental impacts also have a financial impact and hence accountants should be encouraged to evaluate these decisions and become involved in the environmental management system (EMS). Bennett, Schaltegger and Zvezdov (2011) emphasized that environment and sustainability are comparatively new concerns for businesses which are now documented as insistent and urgent issues for people in general. However, there is relatively little scope for accountants to participate significantly, as their role is usually restricted to supporting the process of publishing reports on their environment performance to key external stakeholders. In these situations, skilled accountants and the extended use of the central accounting systems can assist businesses in managing their environmental and sustainability performances (Bennett et al., 2011). Accordingly, the environmental concerns have become universally agreed massive anxiety, and accounting for managing environmental costs is taking on increasing importance (Savage \& Jasch, 2005).

In this sense, social and environmental accounting research has paid considerable attention to enhance understanding of reporting practices and their contribution to the environmental agenda (Parker, 2005). Gray (2010) emphasized that emergence of 
International Journal of Accounting \& Business Finance Vol.6.No.2 December 2020 Issue. pp. 139 - 157

sustainable development through which social and environmental issues must be addressed has had a growing influence in the accounting literature. There remains a lack of research, particularly in developing countries, on managing environmental costs of organizations linking them with their accounting systems and practices. This research attempts to fill this gap in the accounting literature. Thus, the main purpose of this study is to investigate capabilities of management accounting (MA) systems in managing environmental costs of listed companies in the Sri Lankan context.

\section{Literature Review}

\subsection{Arising Environmental Costs and Related Issues}

Concentrating on increasing environmental costs of organizations and related environmental regulations, United Nations Division for Sustainable Development -UNDSD (2001) revealed that the costs for industry of environmental protection, including pollution reduction, waste management, monitoring, regulatory reporting, legal fees and insurance, have increased rapidly in the past 20 years with increasingly stringent environmental regulations. UNDSD identified environmental issues that may arise with traditional MA systems. Traditional MA systems attribute many of those environmental costs to general overhead accounts, so that product and production managers have no incentive to reduce environmental costs, and also executives are often unaware of the extent of environmental costs. The aggregation of environmental and non-environmental costs in overhead accounts results in their being 'hidden' from management. Thus, there is substantial evidence that management tends to underestimate the extent and growth of such costs (UNDSD, 2001).

Supporting this view, IFAC (2005) also stated that, although many countries around the world have been devoting more attention to environmental concerns along with associated costs, revenues and benefits, it is progressively accepted that traditional accounting practices do not provide sufficient information for EM purposes. EMA is recognized as a new field in accounting that is capable of identifying and handling environmental costs properly so that mitigating related issues and thus, receiving increasing attention. UNDSD (2001) also stated that EMA allows management to identify opportunities for cost savings by identifying, assessing and allocating environmental costs.

In this respect, according to ISO 14001, an Environmental Management System (EMS) is a framework that can be integrated with existing business processes to identify measure, manage and control environmental impacts effectively and hence environmental risks. An EMS is a part of the overall management system, and it establishes the means for improving performance and moving towards environmental sustainability through best practice such as ISO 14001 (ISO, 2000).

\subsection{What are Environmental Costs?}

Jasch (2003) emphasised that the main problem is absence of standard definitions for environmental costs, so that, depending 
on various interests, they include a variety of costs by different groups. Environmental costs comprise both internal and external costs and relate to all costs incurred in relation to environmental damage and protection. Environmental protection costs include costs for prevention, disposal, planning and control, shifting actions and repairing damages that can occur in companies, governments or people. However, the amount of corporate environmental protection expenditure is not directly related to the environmental performance of a company (Jasch, 2003).

Supporting the views of UNDSD (2001) and of IFAC (2005), Jasch (2003) further revealed that most of these costs are usually not traced analytically and attributed to the responsible processes and products; instead simply summed up in general overheads. As a result, organizations often lead to distorted calculations for improvement options and achieved savings, as environmental costs are not fully recorded, and hence environmental protection projects are not recognized and implemented to prevent emissions and waste.

Based on the environmental cost assessment scheme developed for the UNDSD EMA working group, Jasch (2003) identified and analysed environmental costs of a company in Austria under five categories: i) waste and emission treatment, ii) prevention and environmental management, iii) material purchase value of non-product output, iv) processing costs of non-product output, v) environmental earnings (p.670). The analysis reveals that, the highest environmental costs percentage $(80.4 \%)$ is given to the material purchase value of non-product output.

IFAC (2005) also presents almost similar environmental-related cost categories, savings and earnings as indicated below.

Costs: i) Material costs of product output (purchase costs of natural resources such as water and other materials that are converted into products, by-products and packing); ii) Material costs of non-product output (costs of energy, water and other materials that become waste and emissions); iii) Waste and emission control costs (costs for handling, treatment and disposal of waste and emissions; remediation and compensation costs related to environmental damage; and any control-related regulatory compliance costs); iv) Prevention and other EM costs (costs of preventive EM activities, i.e., cleaner production projects, and other EM activities, such as environmental planning and systems, environmental measurement, environmental communication, and other relevant activities); v) Research and development (R\&D) costs related to environmental issues; vi) Less tangible costs (internal and external costs related to less tangible issues, i.e. liability, future regulations, productivity, company image, stakeholder relations, externalities).

Earnings: From sales of scrap or waste (for reuse by another organization); subsidies; sales of excess capacity of waste treatment facilities; insurance reimbursement for environmentalrelated claims; higher profit margins due to environmentally benign products etc. 
Savings: From decrease of materials use and waste generation (as a result of efficiency improvements by implementing preventive EM activities, i.e., on-site recycling, extended producer responsibility, cleaner production, green research and design, green purchasing; and improvements in environmental planning and systems).

This study concerns with above first five cost categories outlined by IFAC (2005).

\subsection{Incorporation of EM into MA}

IFAC (1998) presented four recognizable stages in which MA has evolved, with a different focus in each stage: stage I (prior to 1950) cost determination and financial control; stage II (by 1965) - provision of information for management planning and control; stage III (by 1985) - the reduction of waste in resources used in business processes; stage IV (by 1995); generation or creation of value through the effective use of resources and through the use of technologies.

By reviewing the evolution of MA outlined by IFAC (1998) and interpretations given on that in the literature (Abdel-Kader and Luther 2006; Waweru et al. 2005), it can be suggested that, particularly in the third and fourth stages of the evolution of MA, efforts have been made to incorporate EM into MA practices. In this incorporation, particular attention was given to the reduction of waste in resources used in business processes and also generation or creation of value through the effective use of resources and through the use of technologies. Attempts made in these two
International Journal of Accounting \& Business Finance Vol.6.No.2 December 2020 Issue. pp. 139 - 157

stages relate to the economic impact of EM issues on which this study is based, and also relate to EM-related cost categories, earnings and savings described by IFAC (2005).

The main difference between traditional MA and EMA is that the latter stresses the importance of environmental costs and supplies information on material flows, which helps to improve economic and environmental performance (UNDSD 2001). In the real world EMA ranges from simple adjustments to existing accounting systems to more integrated EMA practices that link traditional physical and monetary information systems. But, regardless of structure and format, it is clear that MA and EMA share many common goals, and EMA approaches eventually will support leading-edge practices of MA (IFAC, 1998). Staniskis and Stasiskiene (2002) also suggest that modification of existing MASs can be relatively inexpensive if they generate significant financial and environmental benefits, and obviously environmental issues should also be reflected in existing FA systems.

\subsection{Environmental Related MA Practices}

Bennett and James (1997, p. 3-4 ) defined environmental-related MA practices as 'the generation, analysis, and use of financial and non-financial information in order to improve corporate environmental and economic performance'. Environment-related MA can make a contribution to both business success and sustainable development. Emerging consensus is that practical environment-related MA is closely related to the development of $\mathrm{ABC}$, which is likely to be more widely adopted in coming years (Bennett and James, 1997). 
Further, as cited by Frost and Wilmshurst (2000), the adoption of environmental-related MA by companies has been widely documented: for example, Bennett and James (1998a), Ditz, Ranganathan and Banks (1995), Epstein (1996); and a number of studies have observed that such practices have resulted in cost savings (Schroeder \& Winter, 1997) and competitive advantage (Porter \& van der Linde, 1995). Supporting this view, IFAC (2005) indicates that EMA is valuable particularly for internal management initiatives with a specific environmental focus, and EMA-type information is also increasingly being used for external reporting purposes.

Munteanu (2013) emphasized that for an organization, application of EMA is necessary to meet business requirements and therefore the potential benefits and likely costs of the implementation should be assessed in the first place. However, EMA can be valuable for a company only if conditions such as support and commitment of top management, the use of coherent methodology, good communication and involvement of stakeholders are met. Latan, Jabbour, Jabbour, Wamba, \& Shahbaz (2018) revealed that there is a positive and significant influence between organizational resources (corporate environmental strategy, top management commitment, and environmental uncertainty) on the use of EMA, so that improving the environmental performance
International Journal of Accounting \& Business Finance Vol.6.No.2 December 2020 Issue. pp. 139 - 157

of companies. Qian, Horisch, and Schaltegger (2018) relating to US, Germany, Australia and Japan, found that even though many firms have applied certain EMA tools, only a few have applied the full range of EMA tools. The empirical analysis disclosed that EMA application has a significantly positive impact on both corporate carbon management and disclosure quality. All These findings confirm the usefulness and importance of EMA as a tool for providing information to achieve superior corporate environmental performance.

With a different view, Fuzi, Habidin, Janudin, and Ong, (2019) examined the relationship between EMA practices (EMAP), EMS and environmental performance (EP), and stated that their study would provide new insights for the EMA area including EMAP and EMS in order to improve EP for the Malaysian manufacturing industry.

Jonäll (2008), through a theoretical study on whether EM or environmental accounting were included within MA or FA revealed that 14 studies were likely to be related to MA and two studies to FA. It concluded that EMA can probably support decision making in companies for better environmental performance today, through structured cost assessment that supports effective decision making, better environmental performance, more effective and future-proofed product mixes, strategies and investments. 


\subsection{Role of Accounting and Accountants in Implementing EMS}

Based on a survey of 500 listed companies in Australia, Wilmshurst and Frost (2001) suggest that accounting and the accountant can play a significant role in the successful implementation of the EMS by bringing the traditional functions of accounting to the EM process. These skills include those of measuring, recording, monitoring and verifying financial data. The EMS could incorporate accounting mechanisms that deal with the valuation of environmental impact, environmental performance evaluation, flow of financial information and the monitoring of the success of implementation of environmentally related actions. (Wilmshurst \& Frost, 2001).

Also they indicate that the role for accountants does not imply that they need to be 'environmental experts'. The accountant can assist in identifying environmental information relevant to decision making, in assessing the reliability of measures and in organizing an EMS that enhances the communication of results in an understandable form. Accountants can also play a key role in monitoring environmental performance positioning as part of the audit team by providing input regarding the verification of financial data, cost-benefit analysis, compliance status and the design and implementation of an EMS to capture the required environmental information. In this respect, the accounting information system can provide a framework for the preparation of environmental information to enable management to meet this accountability obligation (Wilmshurst \& Frost, 2001).
International Journal of Accounting \& Business Finance Vol.6.No.2 December 2020 Issue. pp. 139 - 157

Finally, Wilmshurst \& Frost (2001) revealed that although it is accepted that environmental issues are important, many respondents did not recognize a role that accounting and the accountant could play within EM. Accountant should be able to identify appropriate means to measure and present this information. However, limited participation of the accountant in the EMS might reflect a lack of understanding of the potential role that accounting and the accountant could play as a member of the EMS (Wilmshurst \& Frost, 2001).

Albelda (2011), assessing the potential role of MA practices (investment appraisals, costing systems, budgeting and performance measures) in enhancing environmentally responsible businesses, suggest that budgets and performance measures are better reinforced, overall these four MA techniques might operate as a facilitator mechanism for the environmental management. However, accounting serves a double function: as a facilitator mechanism for the environmental management and as a barrier for a further accountability-based environmental management (Albelda, 2011).

(2016) conveyed relating to Malaysian public listed companies that the extent of EMA implementation was at moderate, and emphasized that the involvement of accountants in companies' environmental activities remains lacking, consistent with an earlier suggestion that the role of accounting in environmental domains is minimal (Lodhia, 
2003; Collins et al., 2011; Deegan, 2013; Hopwood, 2009). Mokhtar et al. (2016) also revealed that complying with environmental or sustainability regulations, companies placed a greater prominence on environmental cost effectiveness activities than the measurement and integration of environmental information into their existing MASs.

Supporting these findings, Tam Le, Nguyen and Phan (2019) indicated six factors that positively influence the application of EMA practices: government enforcement, stakeholder interest, positive environmental strategies, community expectations, professional education network, and financial condition, of which, government enforcement has the most significant and positive relationship with the adoption of EMA. On the other hand, it seems that the application of EMA positively influences financial efficiency and environmental efficiency. In line with many previous studies, they further stated that environmental efficiency also strongly positively affects financial efficiency. Thus, innovative solutions to reduce environmental pollution can promote enterprises' profitability. This highlights the importance of maintaining EMA for a business entity towards increasing profitability.

Accordingly, the literature review reveals that least attention has been paid to investigating extent of involvement and/or fitness of MA systems in addressing EM issues and thus, there is a gap in the literature in this area particularly relating to developing countries, like Sri Lanka. Thus, this study will provide a considerable contribution to the literature on the phenomena under investigation with an understanding of the level of integration and competencies of MA practices in addressing environmental issues and managing associated costs.

\section{Research Objectives and Meth- odology}

\subsection{Research Objectives}

The main objective of this study is to investigate the way and the extent to which listed companies in Sri Lanka manage environmental costs through their MA systems. In this concern, it first identifies the personnel involved in EM actions sector-wise; and second it investigates the strengths of MA systems in managing EM costs. Third, it analyses the level of significance/ relevance of applying selected traditional and modern MA techniques in taking EM measures and managing costs.

\subsection{Research Methodology}

\subsubsection{Research approach, theoretical drive, core component and supplementary component}

By applying Mixed Method Research (MMR) approach, this study focuses on its one paradigms 'QUAN + qual' out of eight paradigms delineated by Morse (2010, p. 341). MMR approach enables the researcher in collecting and analysing both quantitative and qualitative data to obtain meaningful findings and interpretations, while reaching sound conclusions. Through this MMR approach, strengths are to be capitalized while 
the weaknesses offset that are seen to be in applying either quantitative or qualitative research method alone for a study (Bryman \& Bell, 2007). In this respect, the theoretical drive is quantitative (signified as QUAN) which is also reflected as the core component and complete method for this study that is capable of answering most of research questions. Then, supplementary component is identified as 'qual' which is used to obtain answers for the rest of the questions that could not be covered with complete methods (here quantitative method signified as core component).

\subsubsection{Sample and Population}

Using multi-stage purposeful sampling method, 42 companies were selected, representing five industry sectors out of twenty sectors listed in Colombo Stock Exchange: food beverage and tobacco - F\&B (08/22) chemicals and pharmaceuticals - CHEM (03/12), diversified holdings-DVS (05/16), manufacturing - MNF (18/39), and plantation - PLN $(08 / 20)$; accumulating to population of 109 companies. Those five sectors were selected purposefully, demonstrating manufacturing and manufacturing related industries as these are more appropriate and relevant for the study than others like service sectors. The researcher then approached to individual companies using snowball sampling, convenience sampling and purposeful sampling, considering factors such as accessibility, relevance of businesses, and nature of data and information required, so that the sample was the most suitable accessible one for the extents of investigation.

\subsubsection{Data collection and analysis methods}

Data were collected mainly through a questionnaire survey, followed concurrently by discussions with finance executives and environmental managers or personnel involved in handling environmental aspects of companies. The respondents were sent the questionnaire in advance through emails and thus, the researcher could have fruitful discussions with officials with a proper understanding of the questions, to obtain descriptive information with clarifications supplementary to the survey data. Further, it reviewed mainly National Environmental Act No. 47 of 1980, Sri Lanka for legislation enacted for sampled companies; and also reports, prospects, website of Central Environmental Authority (CEA), the governing body of Sri Lanka for administering the Act. This process enabled the researcher to collect data and information together with justifications and examples of the phenomena under investigation. The researcher visited all companies in order to obtain a sound response rate $(100 \%)$ and ensure quality of data.

Using SPSS software, this study organized survey data by coding and numbering questions and answers in the questionnaire. A coding system was applied to identify companies industry-wise, but also protecting their anonymity. There are two points of interface available in MMR design for integrating core (QUAN) and supplemental components (qual) to form a meaningful complete analysis and interpretation: i) 'analytical point of interface' that transforming qual data into numerical form; and 'results point of interface' that adding qual data to QUAN results (Morse, 
International Journal of Accounting \& Business Finance Vol.6.No.2 December 2020 Issue. pp. 139 - 157

2010). In view of that, the researcher identified 'results point of interface' as the suitable position for integrating core component 'QUAN' and supplemental component 'qual'. Because due to difficultness of transforming qualitative data and information into numerical form, it is appropriate to add them together to obtain meaningful complete analysis and interpretations for the study. It mainly used SPSS software for analyzing quantitative data and the main tools of analysis were frequency tables. The qualitative data were analyzed linking them with quantitative analysis, aiming at providing expressive detailed interpretations for the phenomena under investigations.

\section{Contextual Facts of Sampled Companies with Respect to MA Practices and EM Measures}

\subsection{Structure and Size of Companies and Nature of Businesses}

Considering the nature of businesses, the researcher purposefully selected the sample of 42 companies representing five industry sectors, all of which relate to manufacturing and manufacturing-related industries, and deal with manufacturing and selling different types of products for local and/or export markets. On the size of sampled companies, the majority (73.8\% - 31 companies) are large size and $26.2 \%$ (11 companies) are medium size. In the DVS and PLT sectors companies are only large, whereas in the other three sectors the majority are large (F \& B - 6/8, CHEM - 2/3 and MNF - 10/18).

Countries use different definitions for demarcating industries as large, medium and small, based on their level of development. In
Sri Lanka, according to the National Policy Framework for Small and Medium Enterprises (SME) (www.industry.gov.lk), the size in the manufacturing sector is based on the number of employees (between 51 - 300 medium size, and more than 300 - large size) and on annual turnover (Rs. Mn. 251 - 750 medium size and more than Rs. Mn. 750 - large size). Businesses of sampled companies typically include manufacturing and selling of food and beverage products; agro-inputs and chemicals; Garments; baby items, cologne, soaps and other consumer products; Ceramic products; cables, wires; aluminum products; durable products like refrigerators, washing machines; rubber products; building materials; and Tea, rubber, coconuts, palm oil, cinnamon etc.

\subsection{Management Personnel Involved in the}

\section{Survey and Discussions}

In this concern, the researcher intentionally sought to get involved of Senior Management (SM) i.e. finance directors, chief financial controllers, finance managers, and DGM finance rather than middle-level management, such as financial accountants and management accountants. Accordingly, $81 \%$ of the personnel involved in represent SM, while the rest signifies middle level (11.9\% - management accountants; $2.4 \%$ - financial accountants; and $4.7 \%$ - both). Because compared with middle-level personnel, SM are typically more competent to provide descriptive analytical answers to questions with adequate justifications and examples with their vast knowledge and experience, not only in the specific area of concern (i.e., accounting), but 
also in other aspects explored in this research, i.e., EM consideration and actions and related policies and procedures at institutional level.

\section{Findings and Discussions}

It evidences that all listed companies have been taking all essential EM measures in complying with environmental legislation enacted mainly through the National Environmental Act (NEA) No. 47 of 1980, Sri Lanka. Accordingly, this study investigates competencies of MA systems of listed companies in handing EM issues focusing on five environmental cost categories (out of its six categories) presented by IFAC (2005) as detailed out in the section 2.2.

Thus, the findings are presented and described under five main aspects as follows.

\subsection{Positions responsible for EM Activities and/or Managing Environmental Costs}

Findings reveal that, as shown in Table 1, of the sample of 42 , only seven companies

Table 1 Personnel involved in EM activities by industry sector

\begin{tabular}{lcccc}
\hline Industry sector & $\begin{array}{c}\text { Personnel involved in EM activities }- \text { no. of Companies } \\
\text { OML }\end{array}$ & Total \\
& EM & 6 & 1 & \\
\hline F\&B & 1 & 3 & 0 & 8 \\
CHEM & 0 & 3 & 0 & 3 \\
DVS & 2 & 10 & 7 & 5 \\
MNF & 1 & 4 & 1 & 18 \\
PLT & 3 & $\mathbf{2 6}$ & $\mathbf{9}$ & 8 \\
Total & $\mathbf{7}$ & $\mathbf{6 1 . 9}$ & $\mathbf{2 1 . 4}$ & $\mathbf{4 2}$ \\
Precent & $\mathbf{1 6 . 7}$ & $\mathbf{1 0 0}$ \\
\hline
\end{tabular}

Notes: EM - Environmental Manager; OML - Other Middle Level Personnel; OEL - Other Executive

Level Personnel 


\subsection{Strengthening of MA Systems Practiced by Listed Companies in Handing EM Issues}

In view of strength of existing accounting systems in tracking and resolving EM issues, the findings indicate the nonexistence of Environment Management Accounting (EMA) systems or Environmental Management Accountants for the function. Thus, they all make adjustments to existing MA/FA systems to a lesser or greater extent with a view to obtaining information for EM-related decisions and actions in keeping with environmental
International Journal of Accounting \& Business Finance Vol.6.No.2 December 2020 Issue. pp. 139 - 157

sensitivity of the businesses and related information requirements. As illustrated in Table 2, in this respect, most companies depend on more than one option, because they all operate both MA and FA systems on occasion, integrating them to provide information for routine planning and control activities. The most widely used approach is to make a simple adjustment to FAS, called FAS+SA $(67 \% ; 28$ companies), followed closely by MAS+SA (50\%; 21 companies). The least popular is $\mathrm{FAS}+\mathrm{CA}(9.5 \%)$, and $\mathrm{MAS}+\mathrm{CA}$ is the second lowest (19\%).

Table 2 Accounting system/s companies depend on in handling EM issues

\begin{tabular}{lccccc}
\hline Industry Sector & EMAS & FAS+SA & MAS+SA & FAS+CA & MAS+CA \\
\hline F \&B & - & 5 & 6 & - & - \\
CHEM & - & 2 & 3 & - & - \\
DVS & - & 1 & 2 & 1 & 2 \\
MNF & - & 14 & 4 & 2 & 5 \\
PLT & - & 6 & 6 & 1 & 1 \\
Total & - & $\mathbf{2 8}$ & $\mathbf{2 1}$ & $\mathbf{4}$ & $\mathbf{8}$ \\
Percentage (\%) & - & $\mathbf{6 7}$ & $\mathbf{5 0}$ & $\mathbf{9 . 5}$ & $\mathbf{1 9}$
\end{tabular}

Notes: EMAS: Environment Management Accounting (EMA) system; MAS: Management Accounting (MA) system; FAS: Financial Accounting (FA) system; FAS+SA: FA system making simple adjustments for EM activities; MAS+SA: MA system making simple adjustments for EM activities; FAS+CA: FA system making adjustments for EM activities to a considerable extent; MAS+CA: MA system making adjustments for EM activities to a considerable extent.

It further reveals that those who consider $\mathrm{FAS}+\mathrm{CA}$ and $\mathrm{MAS}+\mathrm{CA}$ in addressing $\mathrm{EM}$ issues $(4+8=12$ companies) function with a management accountant and/or environmental manager (representing DVS, MNF and PLT sectors). Also, it is apparent that, in situations where they make simple adjustments for EM activities, they do this more with FAS than with MAS; conversely if they make adjustments to a considerable extent for EM activities, the trend is to do this with MAS rather than FAS. In this respect, most companies depend on more than one option in handling EM issues, as shown in Table 2 because none of them does not operate with EMA systems. Jonäll (2008), in a theoretical study, conveys somewhat supportive findings that emphasise a greater involvement of MA than FA for gaining 
a better environmental performance.

Likewise, IFCA (2005) stated that in the real world EMA ranges from simple adjustments to existing accounting systems to more integrated EMA practices that link traditional physical and monetary information systems. Further evidence can be found in the literature supporting the findings of this study i.e., Staniskis and Stasiskiene (2002), suggest that modification of existing MA systems can be relatively inexpensive if they generate significant financial and environmental benefits by reflecting environmental issues. Meanwhile Jasch (2003) revealed fairly supportive views that most of environmental costs are usually not traced analytically and attributed to the responsible processes and products; instead they gathered in general overheads leading to distorted calculations as environmental costs are not fully recorded.

The findings further suggest that, supportive to the views of IFAC (2005), typically all companies maintain their MA systems adequately for their own information requirements to provide information on volume and/or monetary basis, whichever is necessary in their circumstances. Moreover, the results indicate that all companies normally review their MA systems and make revisions to existing systems when revision is required to ensure that they can better respond to contemporary information needs of companies. In this sense, they can have an opportunity to re-think about present-day information requirements in handling EM issues too. However, they normally manage environmental costs by incorporating them into overheads of routine business operations International Journal of Accounting \& Business Finance
International Journal of Accounting \& Business Finance Vol.6.No.2 December 2020 Issue. pp. 139 - 157 so that they face with difficulties to some extent in managing such EM costs properly.

\subsection{Relevance/Significance of MA Techniques in View of EM Activities}

Of the twelve MA techniques considered, traditional MA techniques (except for transfer pricing) seem to be rather important than modern MA techniques for EM considerations and decisions as shown in Table 3.

Accordingly, budgeting is extensively important in taking mitigating activities for EM issues in relation to all cost categories investigated, signifying by $76.2 \%$ of respondents as high and by $23.8 \%$ as moderate. Further, product costing and standard costing have exhibited greater importance in planning and controlling products and associated costs, including EM-related costs, in ensuring the efficient use of resources by minimising waste. Product costing assists companies to manage costs of pollution control and preventive EM activities to a lesser extent, because satisfactory levels of requirements are largely determined by legislation.

$$
\text { Performance evaluation }
$$
indicates above average application, probably due to there not yet being established environment-related performance measures by most companies, and product pricing appears identical, as the whole PLT sector and some in other sectors do not use the techniques for EM decisions. In whole PLT sector, the prices are determined at respective auctions taken place weekly or fortnightly, thus individual companies have no power to determine prices for their products. Transfer pricing shows the lowest application, confirming its unsuitability for EM purposes. 
Table 3 Level of importance of MA practices in making decisions relating to EM activities

EM activities - Number of Companies

MA Techniques

High $\quad$ Moderate $\%$ Low $\quad \%$ Unimportant $\quad \%$

Rank

\section{Traditional MA}

\section{Practices}

$\begin{array}{lccccccccc}\text { Budgeting } & 32 & 76.2 & 10 & 23.8 & - & - & - & - & \mathbf{1} \\ \text { Standard costing } & 23 & 54.8 & 15 & 35.7 & 4 & 9.5 & - & - & \mathbf{3} \\ \text { Product costing } & 21 & 50.0 & 21 & 50.0 & & & - & - & \mathbf{2} \\ \text { Product pricing } & 4 & 9.5 & 12 & 28.6 & 21 & 50.0 & 5 & 11.9 & \mathbf{5} \\ \begin{array}{l}\text { Transfer pricing } \\ \begin{array}{l}\text { Performance } \\ \text { evaluation }\end{array}\end{array} & 1 & 2.4 & 3 & 7.1 & 18 & 42.9 & 20 & 47.6 & \mathbf{9} \\ \end{array}$

\section{Modern MA}

\section{Practices}

\begin{tabular}{lccccccccc} 
ABC system & 4 & 9.5 & 9 & 21.4 & 6 & 14.3 & 23 & 54.8 & $\mathbf{8}$ \\
Target costing & 4 & 9.5 & 16 & 38.1 & 12 & 28.6 & 10 & 23.8 & $\mathbf{6}$ \\
Kaizen costing & 1 & 2.4 & 9 & 21.5 & 15 & 35.7 & 17 & 40.5 & $\mathbf{8}$ \\
Balanced score card & 2 & 4.8 & 6 & 14.3 & 15 & 35.7 & 19 & 45.2 & $\mathbf{8}$ \\
Benchmarking & 2 & 4.8 & 14 & 33.3 & 20 & 47.6 & 6 & 14.3 & 7 \\
JIT systems & - & - & - & - & - & - & 42 & 100 & $\mathbf{1 0}$ \\
\hline
\end{tabular}

Notes: The ranking was based on values obtained by (high*3) $+\left(\right.$ moderate*2) $+\left(\right.$ low $\left.^{*} 1\right)$ 
International Journal of Accounting \& Business Finance Vol.6.No.2 December 2020 Issue. pp. 139 - 157

Albelda (2011) presented somewhat supportive findings assessing the potential role of MA

practices that budgets and performance measures are better reinforced in managing EM costs.

Considering the importance of modern MA techniques for EM decisions, the findings suggest that, except for the PLT sector due to its inapplicability as illustrated above, other sectors have shown above average prominence in target costing with respect to EM activities, particularly in planning and controlling production processes that ensure efficient use of materials, water and energy by minimising waste. Benchmarking is considered by all sectors at moderate level. Some companies apply benchmarking in adopting sound EM measures, such as extraction methods or using natural resources with minimum wastage in a sustainable manner, initiating pollution control measures and taking preventive actions. Most PLT and CHEM companies apply best practices adopted from other estates or companies and from international collaboration.

However, $\mathrm{ABC}$ has shown rather less importance for making EM decisions, probably due to approximately $50 \%$ of companies on average not using the technique ( $\mathrm{F} \& \mathrm{~B}$ $38 \%$; CHEM- 33\%; DVS- 60\%; MNF- 28\%; PLT-100\% applied the ABC). Even though all companies have not been using $\mathrm{ABC}$, those who apply the technique use such information to a larger extent to make sound decisions in managing environmental costs. This finding is confirmed in the literature (Frost and Wilmshurst, 2000; UNDSD, 2001; Staniskis \& Stasiskiene, 2002, 2006; Wilmshurst and Frost,
2001; Russell et al., 1994; Vasile and Man, 2012; and IFAC, 2005), which has reported the lower capability of traditional MA systems in adequately monitoring and allocating environmental costs. Compared to other sectors, the PLT sector uses ABC systems more prominently in managing environmental costs in relation to all EM cost categories, because they are already familiar with all activities and related costs throughout the whole business process. Moreover, the PLT sector is, as discussed, more environmentally sensitive and thus more responsive to EM issues than other sectors.

However, with regard to EM decisions, Kaizen costing and the balanced scorecard are accorded lowest importance, mainly because these techniques were not applied by nearly a half and a third of companies consistently, and JIT systems are unimportant at all (none apply it). The findings further reveal that, except for budgeting, all techniques considered have shown their inapplicability for R \& D. Respondents state that, in a situation where R\&D (with environmental perspectives) receives least attention by listed companies, they use budgeting for R\&D to the extent that they have planned and implemented.

In particular, compared to other sectors, the PLT sector has shown greater ability in this regard, applying suitable EM strategies and taking actions as an industry that deals with agricultural products and with international markets. Such a greater ability in the PLT sector is influenced by their full application (100\%) of modern MA techniques $(\mathrm{ABC}, \mathrm{ABB})$ and greater involvement in 
managing environmental costs because it is a sector with high environmental potential and with international collaboration and agreements. These findings are consistent with those of Bennett and James (1997) that practical environment-related MA is closely related to the development of ABC. Consequently, PLT companies are more capable of addressing EM issues more effectively, facilitated by appropriate MA systems, than are other sectors. The CHEM sector has also shown a somewhat greater ability in this regard, mostly due to the same factors. However, in some settings, just like most companies in other sectors, PLT companies also do not consider environmental costs separately from other costs. Overall findings of this study support the judgements of UNDSD (2001), IFAC (2005) and Jasch (2003).

\section{Conclusions}

Through legislation (NEA, 1980), it is essential to take EM initiatives to prevent and control pollution, however, the MA systems of most companies have not been improved accordingly to incorporate environmental costs and related performance measures precisely that are required for any businesses in handing EM issues suitably. Schaltegger and Burritt (2000) similarly argued for the importance of designing a MA system in such a way as to better respond to EM issues under the same conditions. In this ground, all take EM measures by making adjustment to existing FA and /or MA systems designed mainly for managing normal business operations. These findings support those of Staniskis and Stasiskiene (2002) and Jasch (2003).
Even though this study considered environmental cost categories outlined by IFAC (2005), in most instances, it could not analyse these cost items relating to exiting MA systems of companies as they normally handle environmental costs by incorporating them into overheads of routine business operations. Consequently, they cannot identify possible environmental costs separately and thus this may lead to lower potential for companies in managing EM costs via their current MA systems. Moreover, companies may have little control over the costs of such EM activities because satisfactory levels of requirements and the importance of such activities are largely determined by legislation. These findings support those of Mokhtar et al. (2016).

Competencies of MA techniques considered differ one to another in managing EM costs, showing greater importance for traditional MA techniques like budgeting, products costing than modern MA techniques like kaizen costing, balanced scorecards. These findings are mostly agreed with those of Albelda (2011). Overall, budgeting, standard costing, product costing, $\mathrm{ABC}, \mathrm{ABB}$ and benchmarking can make a greater contribution in addressing EM issues, but a lower contribution by applying Kaizen costing, BSC, transfer pricing and JIT systems. Even though responding companies have not established proper PE systems for EM initiatives, it is clear that PE techniques can also make a greater contribution in handing EM initiatives effectively.

Compared to other sectors, the PLT sector shows greater ability in managing 
environmental costs through their $\mathrm{ABC}$ systems. Because the PLT sector is more environmentally sensitive and deals with international collaboration and agreements, and thus more responsive to EM issues than other sectors. The CHEM sector has also shown a somewhat greater ability in this regard, mostly due to the same factors. However, in some settings, PLT companies also do not consider environmental costs separately from other costs.

This study provides insights on the level of importance and appropriateness of applying certain traditional and modern MA techniques in addressing EM issues. It suggests companies to assign EM responsibility to all under the close supervision of specialists, i.e. environmental manager and improve awareness among all personnel including accounting staff on environmental impacts of business operations and how to manage associated costs in accordance with legal compliances. This study does not describe environmental legislation nevertheless its awareness and compliance are essential for all in any organizational and/or social contexts. It further suggests improving MA systems and techniques in a way to identify EM related costs separately and establish appropriate performance measures to manage EM costs properly. Agreeing to interpretations of Wilmshurst and Frost (2001), IFAC (2005), Bennett et al. (2011) and Tam Le et al. (2019), this study also suggests that environmental efficiency of a firm intensely leads to enhancing financial efficiency. It thus provides motivation for organizations to improve their accounting systems by incorporating EM measures and associated costs; thereby addressing such
International Journal of Accounting \& Business Finance Vol.6.No.2 December 2020 Issue. pp. 139 - 157

EM issues properly ensuing profitability and survival of the business.

\section{References}

Abdel-Kader, M., \& Luther, R. (2006). Management accounting practices in the British food and drink Industry. British Food Journal, 108 (5), 336-357.

Albelda, E. (2011). The role of management accounting practices as facilitators of the environmental management: Evidence from EMAS organisations. Sustainability Accounting, Management and Policy Journal, 2 (1), 76-100.

Bennett, M., \& James, P. (1997). Enviromental related management accounting: current practices and future trends. Greener Management International, (17), 33-51.

Bennett, M., Schaltegger, S., \& Zvezdov, D. (2011). Environmental management accounting. in Review of management accounting research, Palgrave Macmillan, UK, 53-84.

Bryman, A., \& Bell, E. (2007). Business Research Methods $\left(2^{\text {nd }} \mathrm{ed}\right)$. Oxford University Press, New York.

Burritt, R., Hahn, T. \& Schaltegger, S. (2002). Towards a comprehensive framework for environmental management accountinglinks between business actors and environmental management accounting Tools. Australian Accounting Review, 12(2), 39-50.

Central Environmental Authority (CEA) (2015). Environmental Protection Licensing, EIA/ IEE. http://www.cea.lk/web/index.php/en/ acts-regulations. 
Frost, G.R., \& Wilmshurst, T.D. (2000). The Adoption of Environment-related management accounting: an analysis of corporate environmental sensitivity. Accounting Forum, 24, 344-65.

Fuzi, N. M., Habidin, N. F., Janudin, S.E., \& Ong, S. Y. Y. ( 2019). Environmental management accounting practices, environmental management system and environmental performance for the Malaysian manufacturing industry. International Journal of Business Excellence, 18(1), 120-133.

Gray, R. (2010). Is accounting for sustainability actually accounting for sustainability... and how would we know? An exploration of narratives of organizations and the planet. Accounting, Organisation and Society, 35, 47-62.

International Federation of Accountants (IFAC) (1998). Management Accounting Concepts. International Federation of Accountants, New York.

International Federation of Accountants (IFAC) (2005). Environmental Management Accounting: International Guidance Document. International Federation of Accountants, New York, USA.

International Standards Organization (ISO) (2000). ISO 14001 Environmental Management System Certification. Geneva.

Jasch, C. (2003). The use of Environmental Management Accounting (EMA) for identifying environmental costs. Journal of Cleaner Production, 11(6), 667-676.
International Journal of Accounting \& Business Finance Vol.6.No.2 December 2020 Issue. pp. 139 - 157

Accounting including Environmental Management - a literature review. URL: http://hdl.handle.net/2077/9542

Latan, H., Jabbour, C. J. C., Jabbour, A.B.L. D.S., Wamba, S.F., \& Shahbaz, M. (2018). Effects of environmental strategy, environmental uncertainty and top management's commitment on corporate environmental performance: The role of environmental management accounting. Journal of Cleaner Production, 180, 297-306.

Ministry of Industry and Commerce (2015). National Policy Framework for Small and Medium Enterprises. http://www. industry.gov.lk

Mokhtar N., Jusoh, R. \& Zulkifli, N. (2016). Corporate characteristics and environmental management accounting (EMA) implementation: evidence from Malaysian public listed companies (PLCs). Journal of Cleaner Production, 136, 111-122.

Morse, J. (2010). Procedures and practice of mixed method design: Maintaining control, rigor, and complexity, Sage Handbook of Mixed Methods in Social \& Behavioural Research ( $2^{\text {nd }}$ ed.). Thousand Oaks: Sage, $339-53$.

Munteanu, A. R. (2013). Environmental Management Accounting (EMA) Implementation: Motivation and Expected Results from a Business Perspectives. Research Gate, 164-173.

NEA (1980). National Environmental Act No. 47 of 1980. Sri Lanka.

Parker, L.D. (2005). Social and environmental 
accountability research: A view from the commentary box. Accounting, Auditing \& Accountability Journal, 18(6), 842-60.

Qian, W., Horisch, J. \& Schaltegger, S. (2018). Environmental management accounting and its effects on carbon management and disclosure quality. Journal of Cleaner Production, 174, 1608-1619.

Savage, D., \& Jasch, C. (2005). International guidance document on environmental management accounting. International Federation of Accountant (IFAC), New York, USA.

Sri Lanka Standards Institution (SLSI) (2012a). SLSI ISO 14001: Environmental Management System Certification. Sri Lanka Standards Institution, Colombo, Sri Lanka.

Sri Lanka Standards Institution (SLSI) (2013), Training Prospectus. Sri Lanka Standards Institution, Colombo, Sri Lanka.

Sri Lanka Standards Institution (SLSI) (2015). Sri Lanka Standards on Environmental Management: SLSl ISO 14000. Sri Lanka Standards Institution, Colombo, Sri Lanka.

Staniškis, J., \& Stasiškienè, Ž. (2002), Environmental performance evaluationtool for CP investment development and monitoring. Environmental Research, Engineering and Management, 22 (4), 3-10.
International Journal of Accounting \& Business Finance Vol.6.No.2 December 2020 Issue. pp. 139 - 157

Tam Le, T., Nguyen, T. M. A. and Phan, T. T. H. (2019). Environmental Management Accounting and Performance Efficiency in the Vietnamese Construction Material Industry- A Managerial Implication for Sustainable Development. Sustainability, 11, 1-31.

United Nations Division for Sustainable Development (UNDSD) (2001). Environmental Management Accounting Procedures and Principles. United Nations, New York.

Vasile, E., \& Man, M. (2012). Current dimension of environmental management accounting. Procedia-Social and Behavioural Sciences, 62, 566-570.

Veal, A. J. (2005). Business Research Methods: A Managerial Approach ( $2^{\text {nd }} e d$.). Pearson Education Australia, NSW.

Waweru, N.M., Hoque, Z., \& Uliana, E. (2005). A survey of management accounting practices in South Africa. International Journal of Accounting, Auditing and Performance Evaluation, 2(3), 226-63.

Wilmshurst, T.D., \& Frost, G.R. (2001). The Role of Accounting and the Accountant in the Environmental Management System. Business Strategy and the Environment, $10,135-47$. 